\title{
Examining gender differentials and determinants of private health insurance coverage in Zambia
}

\author{
James Mulenga ${ }^{1 *}$, Mulenga C. Mulenga ${ }^{1}$, Katongo M. C. Musonda ${ }^{2}$ and Chilizani Phiri ${ }^{3}$
}

\begin{abstract}
Background: Health insurance is an essential aspect of healthcare. This is because it enables the insured to acquire timely and essential healthcare services, besides offering financial protection from catastrophic treatment costs. This paper seeks to establish gender differentials and determinants of health insurance coverage in Zambia.

Methods: The data used in this study was obtained from the 2018 Zambia Demographic and Health Survey. Data were analyzed using STATA 13.0 software and focused on descriptive and Probit regression analyses.

Results: The study reveals that for women and men, age, wealth category, education, and professional occupation are positively associated with health insurance while being self-employed in the agricultural sector negatively influences health insurance coverage for both sexes. Other variables have gender-specific effects. For instance, being in marital union and having a clerical occupation increases the probability of having health insurance for women while being in the services, skilled, and unskilled manual occupations increases the probability of having health insurance for men. Further, residing in rural areas reduces the probability of having health insurance for men.

Conclusion: The study concludes that there are differences in factors that influence health insurance between women and men. Hence, this study highlights the need to enhance health insurance coverage by addressing the different factors that influence health insurance coverage among men and women. These factors include enhancing education, job creation, diversifying insurance schemes, and gender consideration in the design of National Health Insurance Scheme.
\end{abstract}

Keywords: Health insurance, Coverage, Gender, ZDHS, Zambia

\section{Background}

Health insurance is one of the mechanisms of financing healthcare systems in many countries. Health insurance pools risks and ensures that the insured are protected financially against unexpected catastrophic health treatment costs, which may arise from unpredictable illness or injury [1]. Thus, risk and uncertainty regarding the timing and cost of treatment compel individuals to sign-

\footnotetext{
*Correspondence: nileshmulenga@gmail.com

'Department of Economics, School of Social Science, Mulungushi University, Kabwe, Zambia

Full list of author information is available at the end of the article
}

up for health insurance schemes. Membership in such health insurance schemes brings forth various advantages to the insured and society at large. Through health insurance, individuals can get financial protection and avoid being thrown into dire financial vulnerability and poverty in times of illness or injury, through health insurance [2]. Health insurance thus enables insured families to effectively manage their savings, which could be wiped out in case of sudden illness or injury. It also enables the insured to have access to timely and quality healthcare services which can help achieve Universal Health Coverage (UHC). 
Notwithstanding its importance to the insured and society, health insurance coverage is generally low in most developing countries [3]. Moreover, health insurance may not be equally distributed among men and women in a particular country. Women face greater challenges in the market for health insurance and are more likely to have higher direct healthcare expenses in comparison to men [4]. This poses a challenge to the realization of the Sustainable Development Goal (SDG) number 3, aimed at "ensuring healthy lives and promoting wellbeing for all at all ages" and in particular target 3.8, which focuses on "achieving universal health coverage, including financial risk protection, access to quality essential healthcare services and access to safe, effective, quality and affordable essential medicines and vaccines for all" [5]. Adequate provision of healthcare, as well as healthcare financing systems that ensure access to adequate care regardless of ability to pay, is significant to achieve target 3.8. Achieving this target requires strengthening health systems, as well as having a robust financing structure and reducing out-of-pocket expenditure. It is a widely acknowledged fact that an efficient health financing system is critical to the achievement of UHC $[6,7]$.

Various studies have attributed healthcare utilization and health-seeking behavior to health insurance coverage [3, 8-10]. A study in Tanzania by Kibusi, Sunguya, Kimunai, et al. [11] established that having health insurance enhanced antenatal care visits. Another study undertaken in Ghana contended that being insured increased the probability of health facility deliveries [12]. In Kenya, Were, et al. [13] observed that health insurance enhanced the utilization of obstetric health services among HIV positive pregnant women. It has further been established that health insurance increases the use of private health services and lowers out-of-pocket payments [14]. These studies provide a link between health insurance and healthcare access as well as highlighting the importance of health insurance in the drive towards UHC.

Globally, three common types of health insurance schemes can be identified: Social Health Insurance (SHI), Community Based Health Insurance (CBHI), and Private Health Insurance (PHI). These different schemes vary in their requirements and coverage. $\mathrm{SHI}$ is a mandatory scheme in which individuals are compelled by law to enrol and pay a legally specified amount of premium. The benefits that accrue to those who are insured under this scheme are also determined by law. Many SHI schemes operate according to the solidarity principle where people contribute based on their ability to pay but enjoy the benefits according to needs. CBHI schemes are highly diverse and defy efforts to arrive at a single definition. However, CBHI schemes are usually based on community membership and cover individuals who are excluded from other forms of health insurance. Premiums under CBHI can be paid in cash or kind. The PHI is generally voluntary but may be compulsory too. Under this scheme, premiums are calculated based on the risks of the buyers of health insurance and may vary from insurer to insurer. PHI is a common type of health insurance scheme which plays an important role in most countries as a source of coverage for the population, complementing and supplementing the SHI on services not covered [15]. The scheme lacks the solidarity principle because it targets the well-to-do [16]. PHI is usually characterized by adverse selection, creamskimming, and moral hazard problems.

Private health insurance (PHI) plays a critical role in health financing. It provides health insurance coverage for people who are not covered by social health insurance (SHI). In addition, it plays supplementary and complementary roles to public health insurance schemes. PHI can supplement SHIs by providing alternative coverage for healthcare institutions and healthcare services excluded from SHIs arrangements [17]. PHI can also compliment SHIs by providing double cover to individuals on SHI schemes. However, the existence of PHI is threatened by SHIs. A study by Jin, Hou, and Zhang [18] contends that public health insurance can push out private insurance. Another study by Zikusooka and Kyomuhangi [17] warned that SHI can negatively affect private health insurance schemes because employers shift to mandatory SHIs. To ensure an effective healthcare financing system (resource mobilisation and risk pooling) to achieve universal health insurance (UHC), there is a need to encourage the co-existence of SHI with the PHI, with PHI supplementing and complementing the SHI.

\section{Health financing in Zambia}

Before the implementation of the National Health Insurance Scheme (NHIS) in Zambia, financing of the health sector was mainly from general taxes, donor support, out-of-pocket payments, and PHI [19]. Total health expenditure as a percentage of total government expenditure in Zambia is low, as is the case in many developing countries. Zambia has not met the target set by the Abuja Declaration of having 15\% of government annual expenditure allocated to the health sector. In recent years, government expenditure towards the health sector has consistently been below $15 \%$ of the general government expenditure. Figure 1 depicts government expenditure towards the health sector for the period 2000 to 2016. Zambia's health expenditure is mainly dominated by external funding (42\%), followed by general taxes (39\%) and out-of-pocket payments (13\%) [6].

Over the past years, the contribution of health insurance has generally been very low in Zambia. PHI has been very small, fragmented, and generally employerbased (low-cost prepayment scheme), although other 


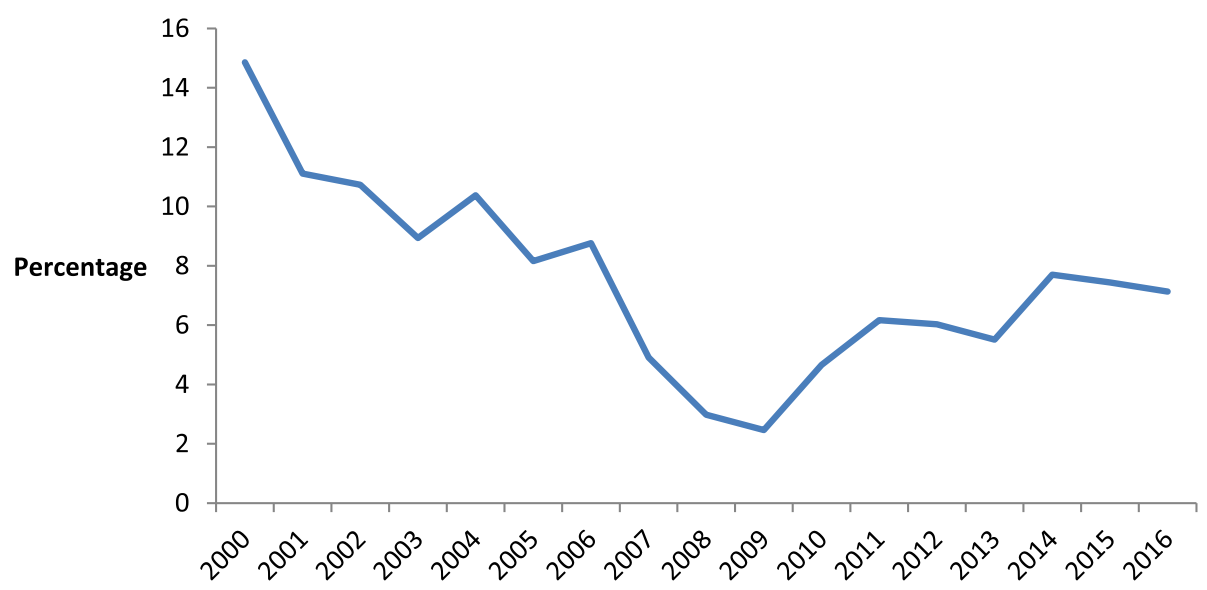

Fig. 1 Trends in domestic general government health expenditure as a percentage of general government expenditure in Zambia. Source: Constructed using the World Development Indicators [6]

schemes like social security and community-based schemes also exist [20, 21]. Figure 2 shows trends in health insurance for men and women in Zambia. The figure shows that, generally, health insurance coverage varies by sex in Zambia. Further, the figure shows a sharp decline in health insurance coverage among both sexes from 2007 to 2013. Between 2013 and 2018, health insurance coverage remained the same for men but declined slightly among women. Hence, health insurance coverage was generally dominated by men between 2007 and 2018, despite insurance coverage being low among both sexes. For instance, in 2018, 3\% of men were insured while only $2 \%$ of women had health insurance coverage. This represents a sharp decline in coverage, from 8 and $9 \%$ among women and men, respectively reported in the 2007 Zambia Demographic and Health Survey (ZDHS). Low rates of health insurance coverage imply that most Zambian citizens have to make direct out-of-pocket payments when they seek healthcare services or be catered for under government taxes. This makes them vulnerable to catastrophic health treatment costs [23].

The government of Zambia implemented the NHIS in 2019 , to enhance the contribution of health insurance to national health financing. The NHIS is based on the solidarity model [24], where the risk is redistributed from healthy individuals to sick ones, from the rich to the poor, from the young to the elderly, and from small families to large families. The NHIS scheme is aimed at ensuring sustainable, predictable, and dedicated financing for the health sector and financial risk cover for Zambians [25].

The introduction of the mandatory NHIS poses a threat to the existence of private health insurance which may ultimately impact the progress towards the achievement of UHC. It is for this reason that this study was undertaken. This paper aims at establishing the gap in

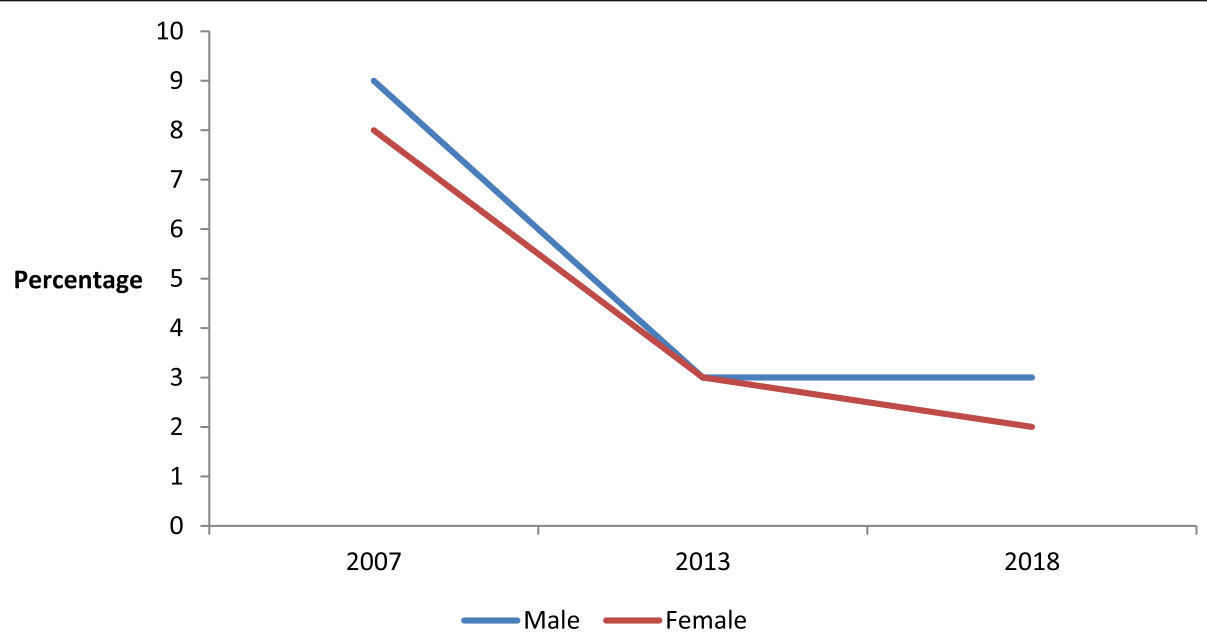

Fig. 2 Trends in health insurance coverage for women and men in Zambia. Source: Constructed from [20-22] 
determinants of health insurance among men and women in Zambia. The study thus provides direction to private health insurance providers and policymakers on the determinants of health insurance between men and women in Zambia. It is envisaged that the output of this study will be used to encourage the growth of private health insurance to supplement and complement the NHIS, and help accelerate the pace towards UHC.

\section{Study objectives}

The study aims at analyzing gender differentials and determinants of health insurance coverage in Zambia. Specifically, the study intends to achieve the following objectives:

1. To establish the difference in levels of health insurance coverage between women and men in Zambia

2. To compare factors influencing health insurance coverage between men and women in Zambia.

\section{Literature review}

There is abundant scholarly work on factors affecting health insurance coverage in various countries around the world. However, few of these studies have focused on comparing the factors influencing health insurance coverage between women and men. The majority of these studies have focused on the determinants of health insurance coverage among women. In Zambia, studies comparing the factors influencing coverage to health insurance between women and men are non-existent. It is the aim of this study to fill up this knowledge gap.

A study by Wang and others [3] examined the levels of health insurance coverage among 30 low and middleincome countries. The research revealed that health insurance coverage was less than $5 \%$ in most of these countries except for eight (8) that had higher than $10 \%$. The study further established that although the gender gap in health insurance coverage was generally narrow, it favoured men in 26 of the 30 countries studied.

Due to patriarchal norms, traditions, and customs women are usually discriminated against and this leads to various gender inequalities in labour force participation rate, progression rate to higher education, access to health insurance among others. As a result of the discrimination and the fact men and women are confronted with varying factors, factors determining health insurance coverage may vary by sex too. Women have greater difficulty in signing up for health insurance due to various barriers. A study in China indicates that men are more likely to have health insurance from employers than women [26] due to lower labour force participation rates among women. This is confirmed by Dewar [27] who contended that the employment gender gap is a strong indicator for health insurance coverage because male-dominated industries have higher odds of health insurance coverage. Keene and Prokos [28] further showed that women with employed spouses had a lower probability of taking up health insurance.

Furthermore, related studies have identified various socioeconomic factors that have had a positive influence on health insurance. These socioeconomic factors include older age [29, 30], higher education level [3, 30-32], urban place of residence, wealth category [3, 21, 32], type of occupation [31], being married [30, 31], media exposure [30], household size, chronic disease, and knowledge of the benefits of and coverage of health insurance [33].

Although several studies $[29,30]$ show that, older age, being male, belonging to a rich household, and employment have positive effects on health insurance coverage, other studies [34-36] have contrasting results. For instance, studies by Duku [34] and Reshmi et al. [35] revealed that female-headed households have a higher likelihood of signing up for health insurance than maleheaded households. Similarly, in Ghana, the people who lived in the households classified as poorest had higher national health insurance enrolments than those who lived in households classified as richest [36].

\section{Methods}

\section{Data}

This study utilized the latest Zambia Demographic and Health Survey (ZDHS) cross-sectional data which was collected under the sixth round of the ZDHS conducted between 18 July 2018 and 24 January 2019. The crosssectional survey was executed by the Zambia Statistical Agency (ZamStats) in partnership with the Ministry of Health $(\mathrm{MOH})$. The ZDHS survey based its sampling on the 2010 national census which was updated to accommodate the changes that occurred between 2010 and 2017.

A nationally representative sample of 12,831 households was selected for the survey using a two-stage stratified sample design. The sampling design included a selection of enumeration areas (EAs) and then a sample of households using systematic sampling. Twenty-five households were picked from each EA, with equal selection probability. According to International Coaching Federation [37], the two-stage stratified sample design was appropriate because it ensures representativeness of the sample, provides a sampling frame in cases where it is not available, enables the best coverage of the target population, and reduces sampling errors arising from more than two-stage sampling.

The 2018 ZDHS used four types of questionnaires to collect data namely: Household, Woman's, Man's, and Biomarker questionnaires. This study used data collected using the Woman's and Man's questionnaires. The woman's questionnaire was distributed to women aged 
15 to 49 in sampled households, while the man's questionnaire was used to collect data from men aged 15 to 59. To ensure that accurate data was collected, the questionnaires were translated into seven major languages. A pretest was also undertaken to ensure that there were no issues with the survey instruments before the full execution of the main survey.

The Institutional Review Board (IRB) of the ICF and the IRB in Zambia reviewed and approved all the questionnaires as well as Zambia's specific survey protocols, to ensure adherence to ethical standards. The secondary data used in this study was obtained from the DHS Program website and was made available to the researchers on request.

\section{Data analysis}

The Probit Regression Model was used to establish the factors that affect health insurance coverage. The model was estimated using the Maximum Likelihood method to generate marginal effects. The marginal effects show a change in the probability of the outcome variable when the independent variable changes by one unit [38]. This model was motivated by the fact that the dependent variable was binary or categorical. All the analyses were undertaken using STATA 13.0 software. The analysis was undertaken at a 95\% confidence level. Sampling weights were used to adjust for oversampling in the ZDHS and avoid bias that would arise in the estimates, during data analysis. The study used pairwise correlation analysis to check for collinearity among the independent variables.

\section{Variables}

Table 1 presents the variables used for data analysis. The variables were chosen based on existing empirical literature.

\section{Study findings \\ Characteristics of the sample}

Characteristics of the sampled individuals for this study are presented in Table 2. Table 2 shows that $55.9 \%$ of the interviewed women are married while $53 \%$ of the men are married. The figure also shows that the majority of the interviewed women (41.9\%) and men $(39.7 \%)$ are in the age range of 15 to 24 years. In addition, $63.6 \%$ of the interviewed women and $79.8 \%$ of the interviewed men had exposure to some mass media. About $46.6 \%$ of the women are from households classified as rich, while $45.7 \%$ of the men are from rich households. The majority of the women have primary education $(44.3 \%)$ while the majority of the men $(48.8 \%)$ have secondary education. About $53.4 \%$ of the women and $55.9 \%$ of the men reside in rural areas. In terms of occupation, a higher percentage $(47.9 \%)$ of the interviewed women reported not being employed, while the majority of the men (25.4\%) are self-employed in the agricultural sector.

\section{Bivariate analysis of health insurance coverage among women and men in Zambia}

Table 3 presents the percentage distribution of health insurance coverage in Zambia by sex and socioeconomic characteristics. The table indicates that among insured men $4 \%$ were in marital union while $2.1 \%$ were not in

Table 1 Independent and Dependent Variables

\begin{tabular}{|c|c|c|}
\hline \multicolumn{3}{|c|}{ DEPENDENT VARIABLE } \\
\hline Variable Name & Description & Recode \\
\hline $\begin{array}{l}\text { Health Insurance } \\
\text { coverage }\end{array}$ & Insured or not insured & Not insured $=0$, insured $=1$ \\
\hline \multicolumn{3}{|c|}{ INDEPENDENT VARIABLES } \\
\hline Variable Name & Description & Recode \\
\hline Age & $\begin{array}{l}\text { Age of respondent in years } \\
\text { (grouped) }\end{array}$ & $15-24=0,25-34=1,35-44=2,44$ and above $=3$ \\
\hline Marital Status & $\begin{array}{l}\text { In marital union or not in marital } \\
\text { union }\end{array}$ & Not in marital union $=0$, in marital union $=1$ \\
\hline Education & Education in single years & No recode \\
\hline Occupation & $\begin{array}{l}\text { Respondents type of occupation } \\
\text { (grouped) }\end{array}$ & $\begin{array}{l}\text { Not Working }=0 \text {, Professional }=1 \text {, Clerical }=2 \text {, Sales }=3 \text {, Sales }=4 \text {, Agricultural:Self-employed = 5, } \\
\text { Household and domestic }=6 \text {, Services }=7 \text {, Skilled manual =8, Unskilled Manual }=9\end{array}$ \\
\hline $\begin{array}{l}\text { Type of place of } \\
\text { residence }\end{array}$ & Residing either in rural or urban & Urban $=0$, rural $=1$ \\
\hline Wealth Category & $\begin{array}{l}\text { Household characteristics: Poor, } \\
\text { medium, rich }\end{array}$ & Poor $=0$, medium $=1$, rich $=2$ \\
\hline Media Exposure & $\begin{array}{l}\text { Exposure to TV, Radio, } \\
\text { Newspaper, and Magazines }\end{array}$ & Not exposed $=0$, Exposed 1 \\
\hline
\end{tabular}


Table 2 Characteristics of the study sample: Women versus men

\begin{tabular}{|c|c|c|c|c|}
\hline & FEMALE (\%) & Sample (N) & MALE (\%) & Sample (N) \\
\hline \multicolumn{5}{|l|}{ Marital Status } \\
\hline Not in marital union & 44.1 & 6035 & 47 & 5704 \\
\hline In marital union & 55.9 & 7648 & 53 & 6428 \\
\hline \multicolumn{5}{|l|}{ Age Group } \\
\hline $15-24$ & 41.9 & 5733 & 39.7 & 4813 \\
\hline $25-34$ & 30 & 4100 & 25.6 & 3104 \\
\hline $35-44$ & 21.6 & 2950 & 19.6 & 2377 \\
\hline $45+$ & 6.6 & 900 & 15.2 & 1838 \\
\hline \multicolumn{5}{|l|}{ Media Exposure } \\
\hline No Exposure & 36.4 & 4979 & 20.2 & 2454 \\
\hline Exposed & 63.6 & 8704 & 79.8 & 9678 \\
\hline \multicolumn{5}{|l|}{ Wealth Category } \\
\hline Poor & 35.3 & 4828 & 34.3 & 4164 \\
\hline Middle & 18.1 & 2477 & 20 & 2422 \\
\hline Rich & 46.6 & 6377 & 45.7 & 5546 \\
\hline \multicolumn{5}{|l|}{ Educational level } \\
\hline No education & 7.7 & 1054 & 4.1 & 492 \\
\hline Primary & 44.3 & 6059 & 38.9 & 4722 \\
\hline Secondary & 42.5 & 5816 & 48.8 & 5918 \\
\hline Tertiary & 5.5 & 755 & 8.2 & 1000 \\
\hline \multicolumn{5}{|l|}{ Type of place of residence } \\
\hline Urban & 46.6 & 6374 & 44.1 & 5346 \\
\hline Rural & 53.4 & 7309 & 55.9 & 6786 \\
\hline \multicolumn{5}{|l|}{ Occupation Type } \\
\hline Not Working & 47.9 & 6547 & 20.6 & 2493 \\
\hline Professional & 4 & 550 & 7 & 843 \\
\hline Clerical & 0.5 & 73 & 0.5 & 61 \\
\hline Sales & 15.7 & 2146 & 6.5 & 785 \\
\hline Agriculture - self employed & 17.9 & 2443 & 25.4 & 3074 \\
\hline Household and domestic & 4.4 & 600 & 4.9 & 596 \\
\hline Services & 2.4 & 330 & 3.6 & 432 \\
\hline Skilled manual & 1 & 137 & 15.9 & 1927 \\
\hline Unskilled manual & 6.2 & 844 & 15.8 & 1911 \\
\hline
\end{tabular}

marital union. For insured women, $2.4 \%$ were in marital union while $1.7 \%$. The table also shows that women and men who have the highest proportion (4.4 and $6.7 \%$ respectively) of health insurance belong to rich households. Women and men from poor households have no insurance coverage. The results also show that women and men with tertiary education have the highest proportion of health insurance coverage (21.8 and $24.5 \%$, respectively) in comparison to those who have no education - primary and secondary education. The table further shows that health insurance coverage is highest among women and men in the clerical occupation (29.9 and $21.5 \%$, respectively) and lowest among women and men in the agricultural sector (self-employed) with 0.1 and $0.2 \%$, respectively.

Determinants of health insurance Coverage among men and women

This section presents the results of the Probit regression analysis for determinants of health insurance coverage among women and men in Zambia. These results are presented in Table 4. Table 4 shows the Probit marginal 
Table 3 Percentage of men and women with health insurance according to demographic and socio-economic characteristics

\begin{tabular}{|c|c|c|c|c|c|c|c|c|c|c|}
\hline \multirow{3}{*}{ Variable } & \multicolumn{5}{|l|}{ Men } & \multicolumn{5}{|c|}{ Women } \\
\hline & \multicolumn{2}{|c|}{ Not Insured } & \multicolumn{2}{|c|}{ Insured } & \multirow[t]{2}{*}{$P$-value } & \multicolumn{2}{|c|}{ Not Insured } & \multicolumn{2}{|c|}{ Insured } & \multirow{2}{*}{$\begin{array}{l}\text { P-value } \\
\%\end{array}$} \\
\hline & $\%$ & $\mathrm{Cl}$ & $\%$ & $\mathrm{Cl}$ & & $\%$ & $\mathrm{Cl}$ & $\%$ & $\mathrm{Cl}$ & \\
\hline \multicolumn{11}{|l|}{ Marital union } \\
\hline Not in union & 97.9 & {$[97.2,98.5]$} & 2.1 & {$[1.5,2.8]$} & 0.0000 & 98.3 & {$[97.7,98.8]$} & 1.7 & {$[1.2,2.3]$} & 0.0000 \\
\hline In union & 96 & {$[95.0,96.8]$} & 4 & {$[3.2,5.0]$} & & 97.6 & {$[96.9,98.2]$} & 2.4 & {$[1.8,3.1]$} & \\
\hline \multicolumn{11}{|l|}{ Age Group } \\
\hline $15-24$ & 98.9 & {$[98.0,99.4]$} & 1.1 & {$[0.6,2.0]$} & 0.0000 & 99 & {$[98.5,99.4]$} & 1 & {$[0.6,1.5]$} & 0.0000 \\
\hline $25-34$ & 96.4 & {$[95.3,97.2]$} & 3.6 & {$[2.8,4.7]$} & & 97 & {$[95.9,97.8]$} & 3 & {$[2.2,4.1]$} & \\
\hline $35-44$ & 95.8 & {$[94.3,96.8]$} & 4.2 & {$[3.2,5.7]$} & & 97.2 & {$[96.2,97.9]$} & 2.8 & {$[2.1,3.8]$} & \\
\hline $45+$ & 94.1 & {$[92.2,95.5]$} & 5.9 & {$[4.5,7.8]$} & & 97.9 & {$[96.1,98.9]$} & 2.1 & {$[1.1,3.9]$} & \\
\hline \multicolumn{11}{|l|}{ Media Exposure } \\
\hline No access/exposure & 99.8 & {$[99.5,99.9]$} & 0.2 & {$[0.1,0.5]$} & 0.0000 & 99.8 & {$[99.7,99.9]$} & 0.2 & {$[0.1,0.3]$} & 0.0000 \\
\hline Access to media/exposed & 96.2 & {$[95.3,96.9]$} & 3.8 & {$[3.1,4.7]$} & & 96.9 & {$[96.0,97.6]$} & 3.1 & {$[2.4,4.0]$} & \\
\hline \multicolumn{11}{|l|}{ Wealth Index } \\
\hline Poor & 100 & [99.9100.0] & 0 & {$[0.0,0.1]$} & 0.0000 & 100 & [99.9100.0] & 0 & {$[0.0,0.1]$} & 0.0000 \\
\hline Middle & 99.8 & {$[99.5,99.9]$} & 0.2 & {$[0.1,0.5]$} & & 99.9 & [99.6100.0] & 0.1 & {$[0.0,0.4]$} & \\
\hline Rich & 93.3 & {$[91.9,94.5]$} & 6.7 & {$[5.5,8.1]$} & & 95.6 & {$[94.4,96.6]$} & 4.4 & {$[3.4,5.6]$} & \\
\hline \multicolumn{11}{|l|}{ Education Level } \\
\hline No education & 96.7 & {$[87.4,99.2]$} & 3.3 & {$[0.8,12.6]$} & 0.0000 & 100 & & 0 & & 0.0000 \\
\hline Primary & 99.7 & {$[99.3,99.9]$} & 0.3 & {$[0.1,0.7]$} & & 99.9 & [99.8100.0] & 0.1 & {$[0.0,0.2]$} & \\
\hline Secondary & 98.3 & {$[97.8,98.7]$} & 1.7 & {$[1.3,2.2]$} & & 98.1 & {$[97.2,98.7]$} & 1.9 & {$[1.3,2.8]$} & \\
\hline Tertiary & 75.5 & {$[71.1,79.4]$} & 24.5 & {$[20.6,28.9]$} & & 78.2 & {$[73.0,82.7]$} & 21.8 & {$[17.3,27.0]$} & \\
\hline \multicolumn{11}{|l|}{ Type of place of residence } \\
\hline Urban & 93.9 & {$[92.4,95.1]$} & 6.1 & {$[4.9,7.6]$} & 0.0000 & 96.1 & {$[94.8,97.1]$} & 3.9 & {$[2.9,5.2]$} & 0.0000 \\
\hline Rural & 99.3 & {$[98.9,99.5]$} & 0.7 & {$[0.5,1.1]$} & & 99.6 & {$[99.3,99.7]$} & 0.4 & {$[0.3,0.7]$} & \\
\hline \multicolumn{11}{|l|}{ Occupation } \\
\hline Not working & 99.4 & {$[98.9,99.7]$} & 0.6 & {$[0.3,1.1]$} & 0.0000 & 98.8 & {$[98.3,99.2]$} & 1.2 & {$[0.8,1.7]$} & 0.0000 \\
\hline Professional/technical/managerial & 78.2 & {$[73.7,82.1]$} & 21.8 & {$[17.9,26.3]$} & & 80.8 & {$[75.8,84.9]$} & 19.2 & {$[15.1,24.2]$} & \\
\hline Clerical & 78.5 & {$[58.5,90.5]$} & 21.5 & {$[9.5,41.5]$} & & 70.1 & {$[54.8,82.0]$} & 29.9 & {$[18.0,45.2]$} & \\
\hline Sales & 98.3 & {$[96.6,99.2]$} & 1.7 & {$[0.8,3.4]$} & & 98.6 & {$[97.7,99.1]$} & 1.4 & {$[0.9,2.3]$} & \\
\hline Agriculture:self-employed & 99.8 & [99.4100.0] & 0.2 & {$[0.0,0.6]$} & & 99.9 & [99.4100.0] & 0.1 & {$[0.0,0.6]$} & \\
\hline Household and domestic & 99.2 & {$[97.3,99.7]$} & 0.8 & {$[0.3,2.7]$} & & 98.6 & {$[96.8,99.4]$} & 1.4 & {$[0.6,3.2]$} & \\
\hline Services & 92.8 & {$[88.9,95.4]$} & 7.2 & {$[4.6,11.1]$} & & 95.5 & {$[89.3,98.2]$} & 4.5 & {$[1.8,10.7]$} & \\
\hline Skilled manual & 96.2 & {$[94.8,97.3]$} & 3.8 & {$[2.7,5.2]$} & & 93 & {$[85.4,96.8]$} & 7 & {$[3.2,14.6]$} & \\
\hline Unskilled manual & 98 & {$[96.3,98.9]$} & 2 & {$[1.1,3.7]$} & & 98.7 & {$[97.5,99.3]$} & 1.3 & {$[0.7,2.5]$} & \\
\hline
\end{tabular}

effects and their corresponding probability values ( $p$ values). The results show that being married, being in the 35 to 44 age category, a rich household, higher education, professional, clerical, or agriculture occupation are significantly associated with health insurance among women. For men; age, being from a rich household, higher education, place of residence, being in a profession, agriculture, services, or skilled manual occupations significantly influence health insurance.
The results show that there is an increase in the probability of having health insurance (about 1.15\%) among women in marital union compared to women that are not in marital union. Generally, the probability of having health insurance increases with age for both sexes. For women in the age category 35 to 44 , the probability of having health insurance increases by $0.83 \%$ compared to women in the age group of 15 to 24 . Men in higher age categories ( 25 to 34,35 to 40 , and above 40 ) are more likely to be insured compared to those aged between 15 
Table 4 Probit Regression Analysis of the Factors Influencing Health Insurance Coverage: Women versus Men

\begin{tabular}{|c|c|c|c|c|}
\hline \multirow[b]{2}{*}{ VARIABLE } & \multicolumn{2}{|l|}{ WOMEN } & \multicolumn{2}{|l|}{ MEN } \\
\hline & Marginal Effects (dy/dx) & P-values & Marginal Effects (dy/dx) & $P$-values \\
\hline \multicolumn{5}{|l|}{ Marital Status } \\
\hline Not in Marital Union & 1 & & & \\
\hline In Marital Union & 0.0115 & 0.000 & 0.0053 & 0.137 \\
\hline \multicolumn{5}{|l|}{ Age Group } \\
\hline $15-24$ & 1 & & & \\
\hline $25-34$ & 0.0028 & 0.307 & 0.0091 & 0.019 \\
\hline $35-44$ & 0.0083 & 0.023 & 0.0099 & 0.033 \\
\hline 45 and above & 0.0096 & 0.114 & 0.0213 & 0.000 \\
\hline \multicolumn{5}{|l|}{ Wealth Category } \\
\hline Poor & 1 & & & \\
\hline Middle & 0.0015 & 0.637 & 0.0042 & 0.254 \\
\hline Rich & 0.0172 & 0.000 & 0.0263 & 0.000 \\
\hline Education in single years & 0.0056 & 0.000 & 0.0055 & 0.000 \\
\hline \multicolumn{5}{|l|}{ Type of Place of Residence } \\
\hline Urban & 1 & & & \\
\hline Rural & -0.001 & 0.682 & -0.0083 & 0.005 \\
\hline \multicolumn{5}{|l|}{ Media Exposure } \\
\hline Not Exposed & 1 & & & \\
\hline Exposed & 0.0062 & 0.059 & 0.0074 & 0.238 \\
\hline \multicolumn{5}{|l|}{ Occupation } \\
\hline Not in Employment & 1 & & & \\
\hline Professionals & 0.0095 & 0.024 & 0.0320 & 0.000 \\
\hline Clerical & 0.0387 & 0.007 & 0.0207 & 0.120 \\
\hline Sales & -0.0039 & 0.153 & -0.0038 & 0.383 \\
\hline Agricultural - self employed & -0.011 & 0.003 & -0.0091 & 0.028 \\
\hline Household and domestic & 0.0045 & 0.472 & -0.0039 & 0.507 \\
\hline Services & 0.0006 & 0.902 & 0.0208 & 0.004 \\
\hline Skilled manual & 0.0226 & 0.080 & 0.0113 & 0.011 \\
\hline Unskilled manual & 0.0051 & 0.324 & 0.0122 & 0.023 \\
\hline
\end{tabular}

and 24 years, holding other variables constant. The probability of having health insurance for men in the age categories of 25 to 34,35 to 44 , and above 45 years is 0.91 , 0.99 , and $2.13 \%$ higher than men aged between 15 and 24 years, respectively.

The results also show that men and women from households classified as rich have a higher probability of having health insurance $(1.72 \%$ for women and $2.63 \%$ for men) compared to those from households classified as poor. Further, as the years of education increase by 1 , the probability of having health insurance increases by $0.56 \%$ for women and $0.55 \%$ for men. The results show that men living in rural areas have a lower probability $(0.83 \%)$ of health insurance relative to their urban counterparts. Being in professional and clerical occupations enhances the probability of being insured by 0.95 and
$3.87 \%$, respectively for women. However, being selfemployed in the agricultural sector reduces the probability of having health insurance for women by $1.1 \%$. For men in the professional, services, skilled manual and unskilled manual, the probabilities increase by $3.20,2.08$, 1.13 , and $1.22 \%$, respectively. Being self-employed in the agricultural sector reduces the probability of men having health insurance by $0.91 \%$, similar to women.

\section{Discussion of findings}

This study has established that private health insurance coverage in Zambia has generally been low for both women and men. Similar patterns have been observed by other studies in other developing countries. The results also show that health insurance coverage in Zambia varies with sex, with coverage favouring the male. The 
results of this study are in tandem with the findings of Wang et al. [3] who observed that health insurance coverage in most developing countries was less than 5\% and that the gender gap in health insurance coverage favored men. The study further shows that education, wealth, or occupation do not reduce the health insurance gender gaps.

Further analysis of data using the Probit regression model provides factors that significantly influence the health insurance coverage of women and men in Zambia. According to the results, being in a marital union was found to increase the probability of signing up for health insurance in comparison to not being in a marital union for both sexes. This is possible because people in marital unions can pool resources together and be able to afford health insurance. The finding is consistent with [31] who contended that people who are married have higher a possibility of having health insurance than those who are not married in Ghana. Similar results were observed by Kazungu and Barasa [39] in Kenya and Mulenga et al. [30] in Zambia.

The age of the respondent is also another important factor that increases the probability of signing up for health insurance. It is believed that as individuals age, their health deteriorates at a faster rate than younger individuals. It is for this reason that the elderly are more likely to sign up for health insurance to cover themselves against the heightened risk of illness [40]. These findings are consistent with the findings of other studies [29, 31, 39] undertaken in other countries.

The results of this study further show that men and women from households classified as rich have a higher probability of having health insurance compared to those who live in households classified as poor. A study by Wang et al. [3] in 30 low and middle-income countries and another study by Amu et al. [29] in Ghana, Kenya, Nigeria, and Tanzania had similar findings.

The number of years in education was found to increase the probability of health insurance coverage for both women and men. Education plays an important role in people's lives as it enables individuals to understand their health needs and make informed choices. Education can also enhance healthcare informationseeking behavior and quality decision-making [41]. Education further enables individuals to get well-paying jobs which give them a higher ability to purchase health insurance.

In terms of place of residence, the results show that men who reside in rural areas have a lower probability of having healthcare insurance. This can be attributed to the high levels of poverty among the majority of rural dwellers. In Zambia, $54.4 \%$ of the people live below the national poverty line with $76.6 \%$ in rural areas [42]. People in rural areas are also generally not well educated. Moreover, private insurance companies are located in urban areas [30].

The type of occupation one engages in can greatly influence the demand for and coverage of health insurance. The results indicate that some occupations are associated with an increase in the probability of signing up for health insurance while others decrease the probability of health insurance coverage. It has been established on one hand that, being in professional and clerical occupations increases the probability of signing up for health insurance for both women and men. On the other hand, being self-employed in the agricultural sector reduces the probability of having health insurance for both sexes.

The results of the study further show that men in services, skilled manual, and unskilled manual occupations had an increased probability of having health insurance coverage. Most of these occupations such as professional, clerical, and skilled manual are found in the formal sector characterized by paid jobs. As a result, income generated from such jobs gives an individual greater ability to purchase health insurance. Moreover, in most formal jobs health insurance comes as part of the employment package [43]. In this case, employers fund their employees' medical expenses directly [44] or through a joint employer-employee contributions to a scheme. The agricultural sector is generally a ruralbased and most people engaged in the agricultural sector are usually subsistence self-employed farmers who do not generate enough revenue to afford health insurance.

\section{Policy implications and study limitations}

Based on the results presented, the following are the policy implications of the findings of this study:

The Ministry of General Education must enhance and encourage primary education for all. This is because enhanced education enlightens individuals and enables them to make informed choices. As such, enhancing education can boost health insurance coverage. Hence, enhancing access to education would boost health insurance coverage for both men and women in Zambia, since education is positively associated with health insurance.

Introduction of community health insurance schemes to cover men and women in agriculture. Specifically, those who may not have the cash to pay premiums under the SHI or private health insurance but may have the capacity to pay in kind.

Enhancing employment creation, particularly formal employment, can boost health insurance coverage. This is because cash payments give individuals the ability to pay premiums for health insurance.

Government should consider the findings of this study, taking note of gender differentials, when designing 
policies and strategies under the NHIS. Thus the design of health insurance policies should not be gender blind.

It is worth noting some limitations of this study. The variables used for analysis in this study are limited to the variables found in the 2018 ZDHS. Several key explanatory variables such as premiums, benefits covered under health insurance, quality of healthcare, etc. are not available in the ZDHS. Omission of such important variables from the model may lead to specification bias. In place of premiums, the wealth index acts as a proxy. Thus future research should focus on capturing the important variables.

\section{Conclusion}

The study has observed a drop in health insurance rates in recent years in Zambia. Currently, health insurance coverage is generally very low, although coverage tends to favour the male. The study has also established that there are variations in the factors affecting health insurance coverage among women and men, although they share common factors too. For both men and women; age, wealth category, education, and professional occupation are positively associated with health insurance while being self-employed in the agricultural sector is negatively associated with health insurance coverage. It has been further established that marital union and clerical occupation only increase the probability of signing up for health insurance for women. In the same vein, residing in the rural areas, being in the services, skilled manual and unskilled manual only increases the probability of signing up for health insurance for women. Similarly, residing in rural areas reduces the probability of health insurance. Thus, all these factors point to the fact that there are differentials in the factors that influence health insurance coverage.

\section{Acknowledgements}

The authors wish to acknowledge Dr. Mwaka Siluonde and Mr. Allan Kasongo for the English language Editing.

\section{Authors' contributions}

JM and KMCM conceptualized and initiated the study. JM undertook the data analysis, interpretation and policy implications. MCM did the discussion of findings and reviewed the paper. CP wrote the abstract and conclusion. The author(s) read and approved the final manuscript

\section{Funding}

This study received no funding.

\section{Availability of data and materials}

The secondary data used in this study was obtained from the DHS Program website and was made available to the researchers on request. Data for this study is available at: https://dhsprogram.com/data/dataset/Zambia_StandardDHS_2018.cfm?flag=0

\section{Declarations}

\section{Ethics approval and consent to participate}

Ethical approval was not a requirement in this study since we used secondary data which is available in the public domain. However, before the data was collected by Zambia Statistical Agency, the Institutional Review Board (IRB) of the ICF and the IRB in Zambia reviewed and approved all the questionnaires as well as Zambia's - specific survey protocols, to ensure adherence to ethical issues.

\section{Consent for publication}

Not applicable.

\section{Competing interests}

The authors declare that they have no competing interests.

\section{Author details}

'Department of Economics, School of Social Science, Mulungushi University, Kabwe, Zambia. ${ }^{2}$ National Authorizing Office of the European Development Fund, Ministry of Finance, Lusaka, Zambia. ${ }^{3}$ Department of Economics, Uludag University, Bursa, Turkey.

Received: 19 February 2021 Accepted: 22 October 2021

Published online: 09 November 2021

\section{References}

1. Kusi A, Hansen KS, Asante FA, Enemark U. Does the National Health Insurance Scheme provide financial protection to households in Ghana? BMC Health Services Research. 201; 15(1):331. https://doi.org/10.1186/s12 913-015-0996-8.

2. Gottret PE, Schieber G. Health financing revisited: a Practitioner's guide. Washington, DC: World Bank; 2006. https://doi.org/10.1596/978-0-82136585-4.

3. Wang W, Temsah G, Mallick L. Health Insurance Coverage and Its Impact on Maternal Healthcare Utilization in Low- and Middle-Income Countries. DHS Analytical Studies No. 45. 2013; Rockville, Maryland, USA.

4. Arons J. Women and Obama care; what's at stake for women if the supreme court strikes down the affordable care act? Center for American Progress, 2012.

5. World Health Organization, World Bank. Tracking Universal Health Coverage. The World Bank, number 29042, 2017.

6. Amporfu E. Equity of the premium of the Ghanaian national health insurance scheme and the implications for achieving universal coverage. Int J Equity Health. 2013;12(1):4. https://doi.org/10.1186/1475-9276-12-4.

7. World Health Organization: World Health Report 2010 - Health Systems Financing: The Path to Universal Coverage. 2010, Geneva: World Health Organization.

8. Erlangga D, Suhrcke M, Ali S, Bloor K. The impact of public health insurance on healthcare utilisation, financial protection and health status in low- and middle- income countries: a systematic review. PLoS One. 2019;14(11):1-20. https://doi.org/10.1371/journal.pone.0225237.

9. Benedict O.A., Seth A. Analysing the Influence of Health Insurance Status on Peoples' Health Seeking Behaviour in Rural Ghana", Journal of Tropical Medicine, vol. 2017, Article ID 8486451, 7 pages, 2017. https://doi.org/10.11 $55 / 2017 / 8486451$

10. Jowett M, Deolalikar A, Martinsson P. Health insurance and treatment seeking behaviour: evidence from a low-income country. Health Econ. 2004 Sep;13(9):845-57. 15362177. https://doi.org/10.1002/hec.862.

11. Kibusi SM, Sunguya BF, Kimunai E, Hines CS. Health insurance is important in improving maternal health service utilization in Tanzania-analysis of the 2011/2012 Tanzania HIV/AIDS and malaria indicator survey. BMC Health Serv Res. 2018;18(1):112. https://doi.org/10.1186/s12913-018-2924-1.

12. Agbanyo R, Peprah JA. National health insurance and the choice of delivery facility among expectant mothers in Ghana. Int J Health Econ Manag. 2021; 21(1):27-49. https://doi.org/10.1007/s10754-020-09288-w.

13. Were LPO, Were E, Wamai R, Hogan J, Galarraga O. Effects of social health insurance on access and utilization of obstetric health services: results from HIV+ pregnant women in Kenya. BMC Public Health. 2020;20(1):87. https:// doi.org/10.1186/s12889-020-8186-y\#.

14. Ataguba JO, Goudge J. The Impact of health insurance on health-care utilisation and out-of-pocket payments in South Africa. Geneva Pap Risk Insur Issues Pract. 2012;37(4):633-54. https://doi.org/10.1057/gpp.2012.35.

15. Gottret, P., Schieber, G. Health Financing Revisited: A Practitioner's Guide. Washington, DC: World Bank. (c) World Bank. 2006. https://openknowledge. worldbank.org/handle/10986/7094 License: CC BY 3.0 IGO." 
16. Doetinchem, O., Schramm, B and Jean-Olivier Schmidt, J.O. The Benefits and Challenges of Social Health. Insurance for Developing and Transitional Countries. Federal Ministry for Economic Cooperation and Development (BMZ), (2006).

17. Zikusooka CM. Kyomuhangi R. Private medical pre-payment and insurance. 2007.

18. Jin Y, Hou Z, Zhang D. Determinants of health insurance Coverage among people aged 45 and over in China: who buys public. Private and Multiple Insurance PLoS ONE. 2016;11(8):e0161774. https://doi.org/10.1371/journal. pone.0161774

19. Masiye F, Kaonga O. Determinants of healthcare utilisation and out-ofpocket payments in the context of free public primary healthcare in Zambia. Int J Health Policy Manag. 2016;5(12):693-703. https://doi.org/10.1 5171/IJHPM.2016.65

20. Zambia Statistics Agency, Ministry of Health $(\mathrm{MOH})$ Zambia, and ICF. Zambia Demographic and Health Survey 2018. Lusaka, Zambia, and Rockville. USA: Maryland; 2019

21. Central Statistical Office, Ministry of Health, and ICF International. Zambia Demographic and Health Survey 2013-14. 2014. Rockville, Maryland, USA: Central Statistical Office, Ministry of Health, and ICF International.

22. Central Statistical Office, Ministry of Health, Tropical Diseases Research Centre, University of Zambia, and Macro International Inc. Zambia Demographic and Health Survey 2007. Calverton. Maryland, USA: CSO and Macro International Inc.; 2009.

23. Masiye F, Chansa C. Health Financing in Zambia. World Bank, Washington, DC. 2019. https://openknowledge.worldbank.org/handle/10986/31786 License: CC BY 3.0 IGO

24. The DB. Solidarity Model: Zambia Public Health Insurance Scheme. Policy Monitoring and Research Centre. 2018;2(4) http://dspace.unza.zm/ha ndle/123456789/5828.

25. Chilufya C. Zambia's national health insurance scheme. Health Press Zambia Bull. 2018;2(4):5-16. https://doi.org/10.1080/23288604.2018.1503031.

26. Zhou M, Zhao S, Zhao Z. Gender differences in health insurance coverage in China. Int J Equity Health. 2021;20(1):52. https://doi.org/10.1186/s12939021-01383-9.

27. Dewar D.M. Gender impacts on health insurance coverage: findings for unmarried full-time employees, women's Health Issues, Volume 10, Issue 5, 2000,268-277, https://doi.org/10.1016/S1049-3867(00)00053-0.

28. Keene JR, Prokos AH. Gendered disparities in take-ups of employee health benefits. Sociol Perspect. 2010;53(4):503-26. https://doi.org/10.1525/sop.201 0.53.4.503.

29. Amu H, Dickson KS, Kumi-Kyereme A, Darteh EKM. Understanding variations in health insurance coverage in Ghana, Kenya, Nigeria, and Tanzania: evidence from demographic and health surveys. PLoS One. 2018;13(8): e0201833. https://doi.org/10.1371/journal.pone.0201833.

30. Mulenga JN, Bwalya BB, Gebremeskel Y. Demographic and socio-economic determinants of maternal health insurance coverage in Zambia. Epidemiol Biostat Public Health. 2017;14(1):e12094-1. https://doi.org/10.2427/12094

31. Salari $P$, Akweongo $P$, Aikins M, Tediosi F. Determinants of health insurance enrolment in Ghana: evidence from three national household surveys. Health Policy Plan. 2019;34(8):582-94. https://doi.org/10.1093/heapol/czz079.

32. Kirigia JM, Sambo LG, Nganda B, Mwabu GM, Chatora R, Mwase T. Determinants of health insurance ownership among south African women. BMC Health Serv Res. 2005;5(1):17. https://doi.org/10.1186/1472-6963-5-17.

33. Maina JM, Kithuka P, Tororei S. Perceptions and uptake of health insurance for maternal care in rural Kenya: a cross sectional study. Pan Afr Med J. 2016 Mar 25;23:125. doi: https://doi.org/10.11604/pamj.2016.23.125.8936. PMID: 27279952; PMCID: PMC4885689.

34. Duku SKO. Differences in the determinants of health insurance enrolment among working-age adults in two regions in Ghana. BMC Health Serv Res. 2018;18(1):384. https://doi.org/10.1186/s12913-018-3192-9.

35. Reshmi B, Unnikrishnan B, Nair NS, Guddattu V. Factors determining the enrolment in community-based health insurance schemes: a cross-sectional study from coastal South India. Indian J Community Med. 2018;43(4):312-5. https://doi.org/10.4103/ijcm.IJCM11818.

36. Nsiah-Boateng E, Prah RJ, Nonvignon J. Is enrolment in the national health insurance scheme in Ghana pro-poor? Evidence from the Ghana Living Standards Survey. BMJ Open, 2019; 9(e029419). https://doi:10.1136/ bmjopen-2019-029419.

37. ICF International. Demographic and Health Survey Sampling and Household Listing Manual. MEASURE DHS. Calverton. U.S.A.: Maryland; 2012.
38. Torres-Reyna O. Predicted probabilities and marginal effects after (ordered) logit/probit using margins in Stata. 2014. http://dss.princeton.edu/training/ Panel101.dta

39. Kazungu JS, Barasa EW. Examining levels, distribution and correlates of health insurance coverage in Kenya. Tropical Med Int Health. 2017;22(9): 1175-85. https://doi.org/10.1111/tmi.12912.

40. Kiplagat I, Muriithi M, Kioko U. Determinants of health insurance choice in kenya. ESJ. 2013;9(13) Available from: https://eujournal.org/index.php/esj/a rticle/view/1064

41. Alesane A, Anang BT. Uptake of health insurance by the rural poor in Ghana: determinants and implications for policy. Pan Afr Med J. 2018:31:124 Published 2018 Oct 19. doi:https://doi.org/10.11604/pamj.2018.31.124.16265

42. CSO. 2015 Living Conditions Monitoring Survey Report. Government of the Republic of Zambia, 2016. Lusaka.

43. Ibok NI. Socio-economic and demographic determinants of health insurance consumption. Can Soc Sci. 2012;8(5):64-70. Available from http:// www.cscanada.net/index.php/css/article/view/j.css.1923669720120805.1836. https://doi.org/10.3968/j.css.1923669720120805.1836

44. Hougaard C, Chamberlain D, Aseffa Y. Towards a strategy for micro insurance market development in Zambia: A market and regulatory analysis. Centre for Financial Regulation and Inclusion (Cenfri) research for the ILO, UNCDF, FinMark Trust Zambia and FinMark Trust South Africa. 2009. Cape Town. Available from: http://www.microinsurancecentre.org/resources/ documents/towards-a-strategyfor-microinsurance-development-in-zambia/ download.html.

\section{Publisher's Note}

Springer Nature remains neutral with regard to jurisdictional claims in published maps and institutional affiliations.

Ready to submit your research? Choose BMC and benefit from:

- fast, convenient online submission

- thorough peer review by experienced researchers in your field

- rapid publication on acceptance

- support for research data, including large and complex data types

- gold Open Access which fosters wider collaboration and increased citations

- maximum visibility for your research: over $100 \mathrm{M}$ website views per year

At $\mathrm{BMC}$, research is always in progress.

Learn more biomedcentral.com/submissions 